\title{
A letra e o outro no Japão
}

\author{
Cristina Lindenmeyer Saint-Martin \\ Edson Luiz André de Sousa \\ Mário Eduardo Costa Pereira
}

Em que a particularidade de uma história e de uma língua podem nos ensinar sobre o que há de singular no pathos? Foi com esta intenção que nos reunimos com o Dr. Kunifumi Suzuki em Paris em março de 1993 para conversarmos sobre estas questões. Conhecemos o Dr. Kunifumi Suzuki num seminário de Pierre Fédida onde veio nos falar sobre a diferença sexual no Japão. Dr. Suzuki é psiquiatra e psicanalista e professor na Universidade de Kioto. É membro da Sociedade japonesa de psicopatologia. Trabalhou durante sete anos na França junto ao professor Tatossian em Marseille. Foi lá que pôde se aproximar do ensino de Jacques Lacan. Engajou-se então num longo projeto de trabalho que culminou na tradução para o japonês do seminário III de Jacques Lacan sobre “As psicoses” publicado em 1987 no Japão e o Seminário I “Os escritos técnicos de Freud” publicado em 1991. Publicou também inúmeros textos em francês sobre as especificidades da psicanálise no Japão. Esperamos que o tempo de espera da publicação deste diálogo, que só agora vem a público, ilumine ainda mais as instigantes proposições e problemas colocados por nosso entrevistado. Esta entrevista nos mostra quão rico é para nós transitar pelo Outro de um discurso como forma de sempre recuperar o que há de mais essencial em nossa prática de escuta. 
Edson Sousa: Inicialmente, para nos situarmos um pouco dentro de suas preocupações de investigação, o senhor poderia nos falar da situação da psicanálise no Japão? Em que época ela foi introduzida e começou a se desenvolver?

Kunifumi Suzuki: Inicialmente, haviam "psicanalistas" (seishin bunsekika) que acabaram fundando uma Associação. Não sei as datas exatas desta fundação. Podemos dizer que a psicanálise no Japão está já em sua terceira geração. Creio que antes da guerra já tínhamos a tradução de Freud, contudo havia também a censura, pois ele era considerado um autor de literatura erótica. Podemos dizer que foi depois da Segunda Guerra Mundial que efetivamente começou a psicanálise no Japão. Havia um professor que se chamava Kosawa que estudava psicanálise. Não sei ao certo quem o analisou e onde. Ele é bastante conhecido no Japão.

Depois dele, houve outro professor também bem conhecido Dr. Takéo Doï que escreveu um estudo sobre a "indulgência”. Este texto foi traduzido para o francês. Indulgência em japonês é uma palavra que tem um sentido muito equívoco e ambíguo. Por esta razão é uma palavra que explica de forma precisa o que é a sociedade japonesa. $\mathrm{O}$ professor Takéo Doï era professor da Universidade de Tóquio, uma das universidades mais concorridas no Japão. Ele foi presidente da Associação de Psicanálise, que aderiu à IPA. É uma das únicas associações no Japão. Não há muitas outras instituições.

Portanto, o movimento lacaniano é bastante marginal, ainda não se organizaram em uma instituição psicanalítica.

Edson Sousa: De que forma então tem se organizado este movimento lacaniano? Existem grupos de estudo que se preocupam com a transmissão da psicanálise a partir de uma leitura lacaniana?

Kunifumi Suzuki: Sim. É importante sublinhar que foram publicados alguns livros de orientação lacaniana. Por exemplo Lacan e o problema da clínica é o título do primeiro, publicado em 1990. Este ano (1993), foi publicado um segundo livro. 
Mário Pereira: Gostaria de saber um pouco mais sobre a introdução do ensino de Lacan no Japão. Sabemos que o próprio Lacan escreveu o prefácio de seus Escritos. ${ }^{1}$ Qual era o contexto da psicanálise neste momento e as repercussões desta tradução de Lacan?

Kunifumi Suzuki: Esta tradução foi fruto de um trabalho de equipe cujos membros eram provenientes de muitos horizontes. Havia professores de literatura, psicólogos, psiquiatras. Este trabalho durou muito tempo. A primeira parte da tradução apareceu no início dos anos 1970. O último volume apareceu em 1981. ${ }^{2}$ Portanto, representou um trabalho de 10 anos. Na etapa final, havia apenas um professor que continuou e finalizou o trabalho já que era uma árdua tarefa.

Devo dizer que se trata de uma tradução cuja interpretação tem muitos problemas. A tradução está com muitos erros, portanto a leitura desta tradução torna-se ainda mais difícil que o texto original em francês. Estamos agora com a intenção de refazer esta tradução.

Edson Sousa: Que leitura o senhor faz desta passagem mencionada no prefácio da edição dos Escritos em japonês quando Lacan diz que os japoneses não precisariam ser psicanalisados?

Kunifumi Suzuki: Não compreendo muito bem por que Lacan afirmou isto. Ele tinha alguns conhecimentos da língua japonesa. Alguns japoneses lhe ensinaram nossa língua durante seu "silêncio", ou seja, o período de 1934 até o fim da Segunda Guerra Mundial, época em que ele nada publicou. Dizem também que durante este tempo ele aprendeu a língua chinesa. Portanto, seu conhecimento vem daí. Talvez ele conhecesse a relação entre a língua japonesa e a língua chinesa, os efeitos em nossa língua dos caracteres chineses. Aliás, Lacan mencionou em alguns artigos a diferença entre as duas línguas. O que faz trabalhar o inconsciente do japonês é sobretudo esta diferença entre o sistema de pronúncia e os caracteres.

Edson Sousa: Encontrei uma referência interessante sobre esta questão em um dos seminários de Lacan. Ele diz, ao se referir às formações do inconsciente como os chistes, os lapsos, os sonhos que eles seriam mais específicos na cultura japonesa. Isso me surpreendeu, pois ele se refere à multiplicidade de sentidos do significante e que na língua japonesa haveria uma certa generalização deste jogo com o significante. A reflexão de Lacan indica que o chiste no Japão está na dimensão mesma do discurso mais comum. Portanto, seria de uma presença tão corrente,

1. Ver J. Lacan. “Avis au lecteur japonais”, prefácio da edição japonesa dos Escritos, 1972, texto publicado na Lettre mensuelle de l'Ecole de la Cause freudienne, $\mathrm{n}^{\circ} 3$.

2. Os Escritos foram publicados em três volumes na edição japonesa. 
que seu lugar não seria o mesmo que no Ocidente. Gostaria de saber o que o senhor poderia comentar sobre esta especificidade das formações do inconsciente e em que isto poderia nos esclarecer sobre a singularidade da psicanálise no Japão?

Kunifumi Suzuki: Esta é uma questão difícil de responder. De fato, existe na língua japonesa muitos sinônimos. Sempre, quando falamos, pensamos em Kanji ${ }^{3}$ senão não conseguimos compreender a significação da frase. Mesmo no Japão, há pessoas que não conhecem o alfabeto, que não conseguem escrever, que não conhecem o Kanji. No entanto, isto não impede o acesso à palavra. Então, não podemos afirmar que o efeito do Kanji seja muito importante. Muitos japoneses não conhecem o Kanji.

Mário Pereira: Penso que podemos agora entrar diretamente em nossa questão mais específica sobre a tradução. Quais os grandes problemas que o senhor mesmo encontrou no trabalho de tradução de Lacan para o japonês?

Kunifumi Suzuki: Encontrei problemas em toda parte. Inicialmente, a própria dificuldade do texto de Lacan. No que se refere à diferença de línguas, talvez possamos responder a esta questão da seguinte maneira... O que me pergunto traduzindo Lacan é o seguinte: há diferenças entre os dois sistemas de línguas, diferenças de relações entre sujeitos e significantes. Como pensar a partir daí o sujeito como efeito do significante? É isso que me pergunto sempre. Há grandes diferenças entre as duas línguas tanto como estrutura, quanto como gramática. Isso já mencionei amplamente em meu artigo. ${ }^{4}$ Não suprimimos o sujeito. Em japonês é sobretudo a última palavra da frase que indica o sujeito. Portanto, posso dizer que há algumas especificidades na língua japonesa que convém muito bem ao ensino de Lacan. Por exemplo, o efeito do aprés-coup na fundação do sujeito. Outra questão que me interrogo se refere ao problema da sexualidade. A diferença sexual não me parece a mesma entre as duas culturas. No extremo oriente houve a influência do Confucionismo. Isso é muito antigo. Essa influência é imensa no Japão, pois o Confucionismo regula a sociedade japonesa em vários níveis. Isso acontece tanto no âmbito da família, na relação entre pais e filhos, entre os membros da família, com os vizinhos, entre professores e alunos e mesmo entre as empresas. A China, a

3. Na língua japonesa encontramos dois sistemas de escritura. O Kanji, que é um sistema ideográfico que foi construído por um implante direto dos caracteres chineses; e o Hiragana, sistema fonético em que se pode escrever segundo a forma como se pronuncia. Dentro de um contexto histórico o Kanji ficou mais reservado para os homens e o Hiragana para as mulheres. Aliás, Hiragana em japonês significa “mão das mulheres”.

4. O Dr. Suzuki está se referindo a seu artigo "La différence structurale entre deux langues et la fonction du je”. In Lacan et la Chose Japonaise. Paris: Navarin, 1988. pp. 63-76. 
Coréia e o Japão tiveram muita influência em sua história do Confucionismo. Hoje em dia mudou um pouco. Agora, é a mentalidade ocidental que regula estas relações nesses países.

Cristina Lindenmeyer: Sabemos que o confucionismo foi introduzido por uma questão social. Podemos dizer que ele permitia posicionar as pessoas na sociedade e regular desta forma as relações. Ele parte de uma certa racionalidade na organização desta sociedade, claro, se utilizamos a terminologia ocidental... Gostaria de compreender seu papel específico na problemática da sexualidade, que o senhor mencionou um pouco antes.

Kunifumi Suzuki: O que eu ainda não expliquei a vocês é que a relação sexual é também regulada pelo confucionismo. Por exemplo, as mulheres não podem fumar diante dos homens segundo o confucionismo. Na idade de 7 anos as mulheres e os homens não podem ficar juntos. É claro que é uma regra do confucionismo que não funciona mais atualmente. Mas na história era assim. Os homens e as mulheres tinham uma educação muito diferente. Portanto, pensar os países do extremo oriente nos obriga a considerar esta questão do confucionismo. Quando pensamos na religião no Japão, pensamos sempre no zen e no budismo. É claro, a influência do budismo é importante no Japão, mas além dela não podemos esquecer o confucionismo. Por exemplo, no confucionismo, se é obrigado de se apresentar diante do outro sempre de forma um pouco inferior. Quando se encontra alguém pela primeira vez deve-se mostrar um pouco inferior, um pouquinho tímido. Esta é uma obrigação sobretudo para as mulheres. Portanto, os japoneses e os chineses se mostram um pouco inferiores em relação aos outros. É uma espécie de neurose social, não é mesmo? O que me pergunto é se neste sistema haveria algo a dizer em relação ao ensino da psicanálise.

Cristina Lindenmeyer: Como o senhor vê esta questão?

Kunifumi Suzuki: Há algumas neuroses sociais que não conseguimos explicar completamente. O livro que mencionei há pouco sobre a indulgência mostra o lado feminino do laço social japonês. Ele descreve relações entre mãe e filho, em que não encontramos a presença de uma terceira pessoa, ou seja, o pai. Mas, no meu entender, esta não é uma explicação muito exata. Não podemos permanecer na relação dual por muito tempo. Precisamos de um terceiro na relação se não as conseqüências como sabemos são terríveis. Me pergunto onde está este terceiro elemento e onde situar o lugar do pai. Talvez ele esteja no sistema do confucionismo. Aliás, há um livro escrito por um francês chamado Maurice Pinguet, A morte voluntária no Japão ${ }^{5}$ que mencionei em um dos meus textos, e creio que ele expli-

5. M. Pinguet. La mort voluntaire au Japon. Paris: Gallimard, 1984. 
cou muito bem o laço social que tem efeito de supereu, o qual, por vezes, há o poder de levar alguém à morte voluntária.

Mário Pereira: Parece-me que esta dificuldade em relação à terceira pessoa se exprime também em relação à língua. Estava lendo o artigo de Takatsugu Sasaki ${ }^{6}$ onde ele diz que é quase impossível, na língua japonesa, falar na primeira pessoa do singular em referência à terceira, pois a conversação se faz entre duas segundas pessoas. Ele insiste neste artigo que a estrutura da língua japonesa é a de uma língua privada, uma língua entre duas pessoas. A língua japonesa insistiria sobre a relação dual e ele diz que este terceiro lugar estaria elidido, suprimido. O senhor poderia comentar um pouco esta questão? Na primeira parte de nossa conversa, pareceu-me que o senhor situou o problema em dois níveis: no nível da estrutura da língua e no nível das referências culturais, particularmente a questão da relação entre os sexos.

Edson Sousa: Continuando a questão do Mário, gostaria de sublinhar um pouco o lugar do sujeito do enunciado, do "eu". O senhor desenvolveu em seu artigo a multiplicidade de formas de nomear a primeira pessoa em japonês. ${ }^{7}$ Não seria esta uma diferença fundamental a ser levada em conta?

Kunifumi Suzuki: O sujeito não é o sujeito do enunciado. Lacan insistiu sobre a diferença entre o sujeito da enunciação e o sujeito do enunciado. Não podemos encontrar o sujeito no nível do sujeito do enunciado. O que Lacan queria com o famoso exemplo "tu és aquele que me seguirá(s)”" é mostrar a diferença entre os sujeitos encontrados atrás do "seguirá(s)". Neste momento se trata do "tu". Quando se diz " tu és aquele que me seguirá”, se responde "eu sou aquele que te segue”. Neste momento, há uma diferença entre o "tu" e o sujeito encontrado atrás do "segue”. Esta diferença, que tem sempre efeito de confusão na língua francesa, é o que faz a história do inconsciente, pois ele acumula o efeito de confusão. Então, o

6. T. Sasaki. A psicanálise no Japão. In Lacan et la chose japonaise. Paris: Navarin, 1988. pp. 11-20.

7. O Dr. Suzuki nos lembra as numerosas variações dos pronomes. Para dizer “eu”, por exemplo, podemos escolher entre uma dezena de formas possíveis: watashi, boku, ore, ware, washi, wagahai, onore etc.

8. J. Lacan. O seminário. Livro 3. As psicoses. Aula do 13/6/1956. "Tu e s celui qui me suivra(s)”. No artigo do Dr. Suzuki ele esclarece ainda mais este ponto. "A passagem do pronome relativo "qui', que faz função de tela, não depende do "tu” mas do modo de ser que está atrás deste "seguira(s)" "suivra(s)”. Em sua indeterminação, ele permite e condiciona a formação do Eu.” La différence structurale entre deux langues et la fonction du je. In Lacan et la chose japonaise. Op. cit. 
que é preciso encontrar na língua japonesa é o efeito desta confusão entre os dois sujeitos, ou seja, entre o sujeito do enunciado e o sujeito da enunciação. Portanto, o que é preciso é encontrar este efeito de confusão entre o sujeito suprimido e o sufixo funcional, próprio da língua japonesa.

Mário Pereira: Lendo seu artigo pareceu-me que esta potência superegóica da língua japonesa, que o senhor referiu há pouco, teria relação com o fato de que na língua japonesa o lugar imaginário do sujeito do enunciado não está marcado. Tudo se passa como se a língua falasse de uma lei que fala sozinha, pois não há um sujeito imaginário que fala. O que senhor poderia nos dizer sobre isso?

Kunifumi Suzuki: Por exemplo, quando uma mãe interdita alguma coisa a seu filho, ela não diz normalmente "não faça isto!". Ela dirá sobretudo "se fizeres isto o mundo, os outros, dirão alguma coisa”. Imaginando os outros ela interdita a criança de algo. Isto é muito freqüente no Japão.

Edson Sousa: Há muitos testemunhos de impressões de viagem de pessoas que estiveram no Japão. Num desses depoimentos li algo sobre a diferença sexual. Esta pessoa se surpreendia ao ver como em certos momentos se pode passar de um lugar a outro facilmente. Um funcionário de uma empresa, por exemplo, pode deixar seu trabalho diário e ao sair à noite se vestir como uma mulher. Encontramos aí uma interrogação paradoxal de como nesta cultura, aparentemente bastante controladora, seria permitido uma certa flexibilidade de lugares. Isso talvez aconteça graças a uma indeterminação do lugar do sujeito e as várias formas de se situar. Isto parecer ser bem diferente em relação ao laço social ocidental em que o "masculino" e o "feminino" são, aparentemente, mais determinados. Há também no teatro japonês, no teatro Kabuki, este papel da mulher que é habitualmente feito pelos homens.

Kunifumi Suzuki: Eu me pergunto sobre esta flexibilidade. Mas na cultura francesa encontramos também esta flexibilidade, não é mesmo?

Edson Sousa: Daquilo que o senhor nos falou podemos deduzir que a diferença sexual no Japão se faria mais enfaticamente sobretudo no próprio sistema da língua.

Kunifumi Suzuki: Há um exemplo bem interessante. Um francês que mora no Japão e que tem muitas amigas japonesas. Por esta razão ele fala o japonês como se fosse uma mulher. As francesas que tem um amigo japonês, falam como um homem.

Cristina Lindenmeyer: Você disse há pouco, quando se referia ao livro sobre “indulgência”, que o autor havia mostrado exemplos de palavras bastante ambíguas na língua japonesa. Depois o senhor afirmou que o termo “ambíguo” demonstra 
bem o que é a sociedade japonesa. Gostaria que o senhor falasse um pouco mais sobre esta idéia de "ambíguo"!

Kunifumi Suzuki: Ah, sim... Com isto podemos retomar o problema da flexibilidade. É difícil explicar aqui teoricamente, mas eu posso dar um exemplo. Há no Japão um bar que é um pouco diferente dos daqui. Neste bar há uma mulher que chamamos "mamma", como "mamãe". Muitos homens de negócios, executivos, depois do trabalho vão ao bar para beber, para falar entre eles e com estas mulheres que chamam "mamma". Neste momento, eles podem se comportar como uma criança, um pouco como na relação mãe-filho. Então se é permitido regredir um pouco. Na sociedade japonesa isto é uma espécie de flexibilidade. Durante o trabalho há a obrigação de ser muito masculino. Mas depois do trabalho se pode ser um pouco criança.

No Japão se troca o pronome pessoal para a primeira pessoa do singular segundo o laço social, ou seja, o lugar ocupado em relação aos outros. Troca-se o pronome e os sufixos funcionais também. Por este sistema, se pode mudar facilmente, e com muita flexibilidade, de ação. Se fala de modo diferente com uma mesma pessoa dependendo se estamos no trabalho ou depois do expediente. Portanto, esta escolha do pronome pessoal e do sufixo funcional regula muito bem a relação e se tem a possibilidade de mudar de relação bruscamente, como se dirigir ao outro como tu e como vós, na segunda pessoa do singular ou do plural.

Mário Pereira: Gostaria de lhe colocar uma questão sobre algo que o senhor falou em sua conferência na Universidade de Paris VII ${ }^{9}$ e que penso que toca especialmente a situação da psicanálise no Brasil. Gostaria que o senhor nos falasse um pouco da receptividade às culturas de outros países ocidentais pela cultura japonesa. A psicanálise é, em última instância, uma importação da Europa feita por vocês. O senhor disse, em sua conferência, que existia uma espécie de fantasma japonês no além mar, que lá existiria um país ideal. Por exemplo, no Brasil, todas as coisas que vêm da Europa são, a priori, boas, são melhores que as nossas. A Europa continua funcionando como uma espécie de horizonte que orienta nossas idéias e pesquisas. Como estas questões funcionam no Japão, e particularmente neste momento em que Lacan começa a ser traduzido em japonês?

Kunifumi Suzuki: Este fantasma de que há um país ideal mais além do mar é talvez um fenômeno em quase todos os países fora da Europa. Mas, como já mencionei em meu artigo, nunca tivemos uma experiência de invasão. Isso significa

9. Conferência “A diferença cultural, a diferença sexual e a psicanálise”, em março de 1993 na Universidade de Paris 7, Departamento de Psicopatologia Fundamental. Dirigido por Pierre Fédida. 
que em nosso imaginário os outros países não possuem muita agressividade contra nós. Como o Japão é um país insular então ele é muito bem protegido, o que de uma certa forma evitou que fôssemos invadidos. Inicialmente foi a China e a Coréia que influenciaram muito o Japão e que representavam para nós os países ideais. Depois, foi a Espanha e a Holanda que nos trouxeram muitas coisas da Europa. Depois, no final do século XIX, abrimos nosso país. A partir de 1868, foram sobretudo os países ocidentais que nos influenciaram, sobretudo a França, a Alemanha e a Inglaterra, dependendo da área. Por exemplo, no domínio da lei, foi sobretudo a Alemanha. No domínio da medicina, também a Alemanha. No domínio da marinha tivemos muita influência da Inglaterra. Em relação ao exército foi a França. Estes dois grupos, a marinha e o exército, têm muitas diferenças graças a estas influências. Depois da guerra foram os Estados Unidos que nos influenciaram. Eles continuam ocupando este lugar de país ideal.

Por outro lado, temos também a tradição do nacionalismo, que está muito próximo em nossa imaginação da feminilidade. O nacionalismo da atualidade é bastante influenciado pelo shintoísmo, uma religião originária no Japão que influenciou todas as outras religiões. É uma religião um pouco mística. Nesta religião há muitas mulheres que são praticamente sacerdotes. No domínio do budismo, há muitas poucas mulheres. No ensino do budismo é sempre os homens que se ocupam das teorias. Muitos são os livros sobre budismo escritos em chinês. Somos, então, obrigados a importar livros em chinês. Por isso, são sempre os homens que se ocupam da importação e da tradução.

No que se refere à cultura japonesa, ela guarda muitos traços do confucionismo que foram esquecidos com a influência dos países ocidentais. Na minha opinião, a diferença entre a cultura japonesa e a cultura ocidental é justamente o confucionismo, mesmo hoje. Esquecemos sempre de falar do confucionismo. No ensino do Confucionismo a história não evolui. Então, isto coloca muitos conflitos quando se está ante a cultura ocidental em que o importante é se desenvolver, evoluir. Essas duas mentalidades se opõem.

Mário Pereira: Gostaria de retomar mais algumas questões específicas que concernem à tradução de Lacan para o japonês. Aqui, na França, há um lado produtivo da tradução que eu nomearia como um método de pesquisa em psicanálise. Algumas noções e conceitos, tais como a Nachträglichkeit (aprés-coup) recuperada por Lacan ou a Anlehnung (apoio ou anáclise) por Jean Laplanche, foram desenvolvidos a partir de um trabalho de tradução do texto original. Gostaria de saber como isso se passa com vocês, esta dimensão da pesquisa a partir da tradução do texto.

Kunifumi Suzuki: O trabalho de tradução nos envolve muito com a pesquisa. Levamos três anos para traduzir o seminário sobre as psicoses. Encontramos muitas noções novas que nos obrigaram, por vezes, a inventar palavras em japonês 
para as traduzir. Posso dar como exemplo: a tradução do conceito de "simbólico". Para o simbólico de Lacan, inventamos uma palavra especial que não utilizamos na conversação quotidiana e que tem alguma relação com o budismo, com as palavras do budismo. Traduzimos por "Sho Cho Kaï”. "Sho Cho" significa símbolo e "Kaï" quer dizer "mundo”, "espaço”, “rede” também. Esta palavra tem uma conotação um pouco religiosa. Não é possível traduzi-la literalmente.

Edson Sousa: E o conceito de inconsciente, houve algum problema particular para traduzi-lo?

Kunifumi Suzuki: Esta é uma palavra já utilizada na tradução de Freud. Então não tínhamos por que inventá-la. Em japonês é uma palavra muito importante. Ela significa "nada”, "falta”. Hoje em dia se utiliza a expressão inconsciente na conversação cotidiana. Deixei muito do vocabulário lacaniano sem traduzir em japonês.

Edson Sousa: Para concluir, o que significou para o senhor e seus colegas a tradução do Seminário III. As psicoses para o japonês?

Kunifumi Suzuki: A publicação do seminário sobre as psicoses permitiu a um grande número de psiquiatras conhecer o aporte radical do ensino de Lacan, mesmo com as resistências que houveram. Existiram muitos níveis de resistências. Dentro da mesma lógica do que fez Jaspers, por exemplo, que ao diferenciar a compreensão e a explicação, dizia que a psicanálise confundia estes dois níveis, encontramos esta mesma crítica a Lacan. Outra resistência decorre da dificuldade mesma do texto de Lacan.

Nós abordamos a leitura e a tradução do Seminário III a partir de um questionamento e de um interesse sobre a psicopatologia dos esquizofrênicos. Contudo, depois da publicação, percebemos que se tratava muito mais de uma demarcação do campo analítico, ou seja, que ele não explicava propriamente a psicopatologia das psicoses, mas apresentava alguns princípios próprios à psicanálise como, por exemplo, a prioridade do significante em relação ao sujeito. A partir daí nos interessamos particularmente pelos fenômenos neuróticos e a prática analítica. Foi um livro, então, que nos conduziu ao domínio próprio da psicanálise. Eis aí um efeito fundamental desta publicação. ${ }^{10}$

Entrevista recebida para publicação, em junho de 2000.

10. Esta última resposta foi reescrita completamente pelo Dr. Suzuki se remetendo a uma outra entrevista que concedeu na França neste mesmo ano de 1993. 